\title{
Perfil das escolas que visitaram a Área de Relevante Interesse Ecológico Mata de Santa Genebra no ano de 2019
}

\section{Profile of schools that visited the Area of Relevant Ecological Interest Mata de Santa Geneva in 2019}

\author{
Sabrina Kelly Batista Martins, Ismail Barra Nova de Melo, \\ Rita de Cássia Lana, Silvio César Moral Marques
}

\begin{abstract}
RESUMO: A educação e interpretação ambiental, a recreação em contato com a natureza e o turismo ecológico, integram os objetivos do Sistema Nacional de Unidades de Conservação. Segundo as Diretrizes para visitação em Unidades de Conservação (UC), a visitação pode permitir que a sociedade se aproxime da natureza, por meio de vivência no meio natural. Assim, os gestores de unidades de conservação precisam conhecer as características dos seus visitantes, visando elaborar estratégias de planejamento e manejo do uso público como forma para tornar satisfatória a experiência turística. $O$ presente trabalho constitui-se de uma análise do perfil das escolas que visitaram em 2019 a Área de Relevante Interesse Ecológico (ARIE) Mata de Santa Genebra, localizada no município de Campinas (SP). Os dados foram consolidados e analisados por meio de planilhas de Excel. Com o uso do aplicativo Google Earth Pro mapeou-se a distribuição das escolas. Com a análise dos dados foi possível identificar que a maioria das instituições que visitaram a ARIE em 2019 era municipal, principalmente escolas oriundas do município de Campinas. Além disso, o ciclo de educação infantil foi o que mais participou do Programa de Visita Monitorada de Escolas. Conhecer o perfil das escolas que visitam a ARIE se constitui uma ferramenta fundamental para levantar fragilidades e potenciais essenciais à gestão, auxiliando na avaliação das atividades desenvolvidas na UC e na melhoria contínua dos projetos executados.
\end{abstract}

PALAVRAS-CHAVE: Turismo Ecológico; Educação Ambiental; Unidade de Conservação; Educação Básica; Visita Monitorada.

ABSTRACT: Environmental Education and interpretation, recreation in contact with nature and ecological tourism are part of the objectives of the National System of Conservation Units. According to the Guidelines for visitation to Conservation Units UC), visitation may allow society to approach the nature, through living in the natural environment. Thus, managers of protected areas need to know the characteristics of their visitors, aiming to develop planning and management strategies for public use to make the tourist experience satisfactory. This work constitutes a profile analysis of the schools that visited in 2019 the Area of Relevant Ecological Interest of Mata de Santa Geneva, located in the city of Campinas (SP, Brazil). Data were consolidated and analyzed using Excel. Using the Google Earth Pro application, the distribution of schools was mapped. Through data analysis, it was identified that most institutions that visited the Protected Area in 2019 were municipal, mainly schools from the city of Campinas. In addition, the early childhood education cycle was the one that most participated in the Monitored Visit to Schools Program. Knowing the profile of the schools that visit the Protected Area is an essential tool to identify essential weaknesses and potentials for the management, helping to evaluate the activities developed at the UC and continuously improve the implemented projects.

KEYWORDS: Ecological Tourism; Environmental Education; Protected Area; Basic Education; Monitored Visit. 


\section{Introdução}

A educação e interpretação ambiental, bem como a recreação em contato com a natureza e o turismo ecológico, é um dos objetivos do Sistema Nacional de Unidades de Conservação (BRASIL, 2000). Nesse sentido, as ações de Educação Ambiental em unidades de conservação têm por objetivo a mudança de atitude dos indivíduos em relação à área protegida, contribuindo para a conservação da biodiversidade e ao desenvolvimento socioambiental (BRASIL, 2016).

Entende-se por Educação Ambiental os processos pelos quais 0 indivíduo e a coletividade constroem valores sociais, conhecimentos, habilidades, atitudes e competências que são voltadas para a conservação do meio ambiente, sendo um componente essencial e permanente da educação nacional, devendo estar presente, em todos os níveis e modalidades do processo educativo, em caráter formal e não-formal (BRASIL, 1999).

A Educação Ambiental direcionada aos grupos sociais que convivem diretamente com a realidade das unidades de conservação, é uma estratégia essencial para o engajamento da sociedade para a conservação das diversidades natural, cultural e histórica desses territórios (BRASIL, 2016). Segundo as Diretrizes para visitação em Unidades de Conservação (BRASIL, 2006), a visitação pode permitir que a sociedade se aproxime da natureza, por meio de vivência no meio natural. Neste sentido, os gestores de unidades de conservação precisam conhecer as características dos seus visitantes, visando elaborar estratégias de planejamento e manejo do uso público como forma para tornar satisfatória a experiência turística (NIEFER, 2002). O conhecimento do perfil do usuário permite uma melhor qualidade de decisões, possibilitando a aplicação de medidas e técnicas com maior objetividade, racionalizando e otimizando recursos materiais, financeiros e humanos (SAVI, 1997). As unidades de conservação podem colaborar em processos educativos que complementem a educação formal, sendo relevantes como espaços de educação não formal (PALMIERI; MASSABNI, 2020).

A interação entre educação formal e unidades de conservação é importante no processo de discussão e formação de uma sociedade consciente de seus direitos e deveres em relação ao meio ambiente (SILVA; COUTINHO, 2017).

No Município de Campinas-SP, a Política Municipal de Educação Ambiental, criada pela Lei no 14.961, de 06 de janeiro de 2015, define como uma de suas diretrizes fomentar e viabilizar ações socioeducativas nas Unidades de Conservação, parques e outras áreas verdes, à diversos públicos, respeitando as potencialidades de cada espaço, reforçando, assim, a importância dessas áreas como espaços educadores.

A contribuição das Unidades de Conservação no processo educativo é essencial, levando-se em consideração a afetividade do sujeito aluno com o lugar (SILVA; COUTINHO, 2017).

Considerando este contexto, o presente trabalho constitui-se de uma análise do perfil das escolas que visitaram em 2019 a Unidade de Conservação Mata de Santa Genebra, localizada no município de Campinas, levantar fragilidades e potencialidades visando subsidiar o planejamento das ações de visitação na UC. 


\section{Metodologia}

\section{Área de estudo}

A presente pesquisa foi desenvolvida na Área de Relevante Interesse Ecológico (ARIE) Mata de Santa Genebra, unidade de conservação federal, localizada no munícipio de Campinas-SP, no Distrito de Barão Geraldo (BRASIL, 2010), sendo o maior fragmento florestal da Região Metropolitana de Campinas (PPP, 2018) (Figura 1). Trata-se de um remanescente de Mata Atlântica, com uma área de 251,77 hectares, composto por aproximadamente 660 espécies vegetais e 885 espécies animais (MORELLATO; LEITÃOFILHO, 1995), sendo que $92 \%$ se constituem em floresta estacional semidecidual e os outros $8 \%$ em floresta paludosa (BRASIL, 2010).

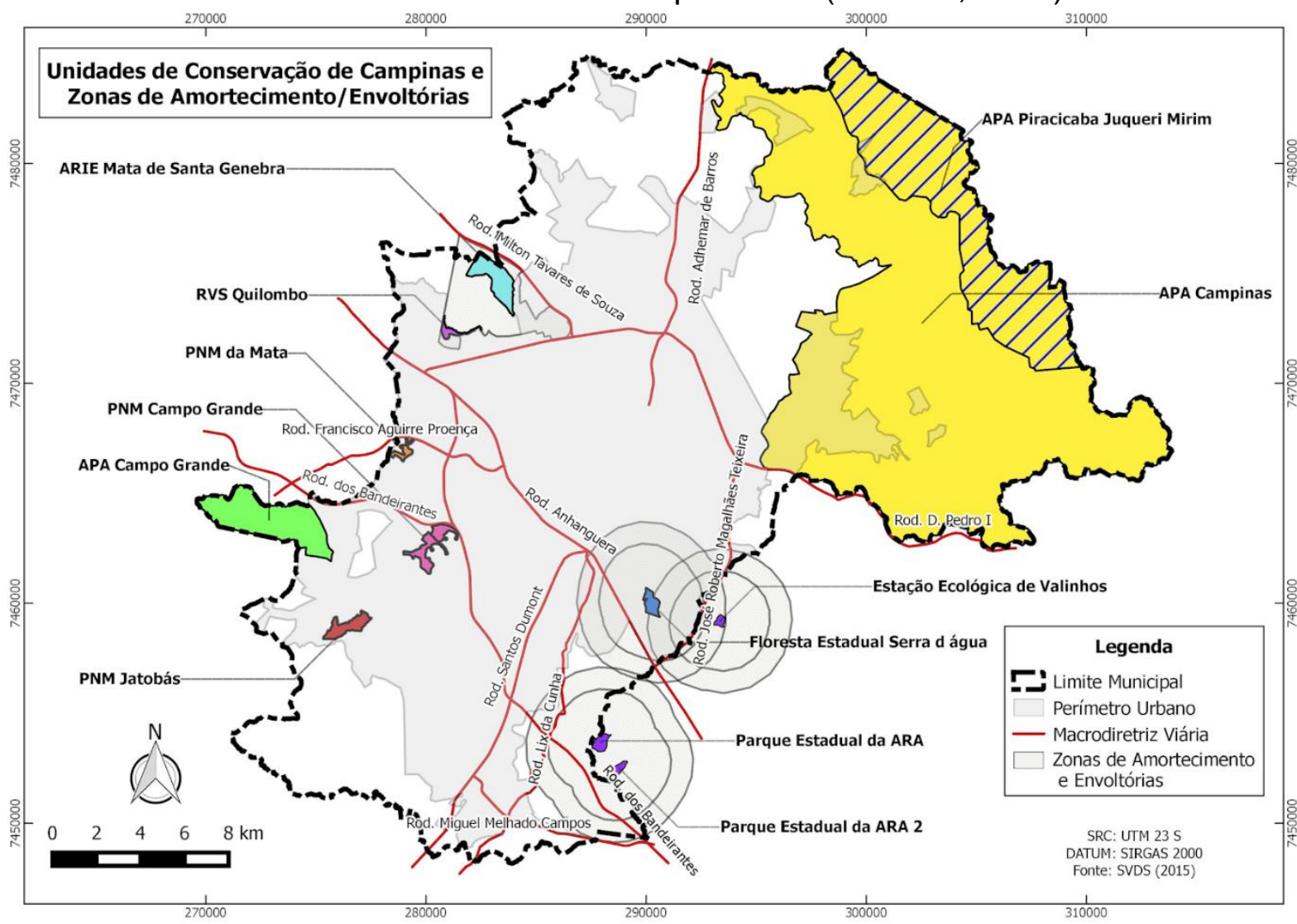

Figura 1: Em azul, o limite da Unidade de Conservação ARIE Mata de Santa Genebra.

Figure 1:Hhighlighted in blue, the limits of the ARIE (Area of Relevant Ecological Interest) Conservation Unit in Mata de Santa Genebra.

Fonte: Secretaria Municipal do Verde, Meio Ambiente e Desenvolvimento Sustentável (2015),

Disponível em: http://www.campinas.sp.gov.br/governo/meio-ambiente/conservacao-danatureza.php.

Source: Municipal Secretariat for Nature Protection, Environment and Sustainable Development (2015), Available at: http://www.campinas.sp.gov.br/governo/meio-ambiente/conservacao-danatureza.php.

A gestão da área é compartilhada entre a Fundação José Pedro de Oliveira (FPJO) e o Instituto Chico Mendes de Conservação da Biodiversidade (ICMBio), sendo o último responsável pela gestão das Unidades de Conservação federais (BRASIL, 2010).

A área mesmo pertencendo ao grupo das Unidades de Conservação de Uso sustentável, é administrada de acordo com a Lei Municipal no 
5.118/1981, que criou a Reserva Florestal Mata de Santa Genebra e a Fundação José Pedro de Oliveira, restringindo seu uso a atividades educativas, de pesquisa científica e de conservação (FUNDAÇÃO JOSÉ PEDRO DE OLIVEIRA, 2018).

As atividades desenvolvidas na Mata de Santa Genebra pela Fundação José Pedro de Oliveira são: uso público e Educação Ambiental, manejo de fauna, manejo de flora, pesquisa e monitoramento, produção de conhecimento, viveiro de mudas nativas, Borboletário, manifestação em licenciamento ambiental e elaboração e execução do plano de contingência para prevenção e combate a incêndios (BRASIL, 2010).

Em relação às atividades de Uso Público, em 1997 foi inaugurado o Centro de Educação Ambiental e a Fundação José Pedro de Oliveira passou a promover atividades de visitação monitorada na área com o Programa de Visita Monitorada de Escolas (FUNDAÇÃO JOSÉ PEDRO DE OLIVEIRA, 2018). As atividades iniciaram-se a estudantes do Ensino Fundamental e Médio e incluíam conceitos de ecologia básica, conservação ambiental, animais peçonhentos, entre outros (op cit., 2018). Com metodologias e objetivos bastante variados o programa vem ocorrendo de maneira ininterrupta desde então e continua a ser requisitado por professores da educação básica de Campinas e municípios do entorno (op cit., 2018).

\section{Fonte de dados}

A fonte de dados utilizada foi o banco de dados do Programa Visita Monitorada de Escolas da Fundação José Pedro de Oliveira, do ano de 2019. Este ano foi marcado por uma mudança na forma de agendamento das visitas, as inscrições passaram a ser realizadas por meio eletrônico, no site da FJPO.

O banco de dados é alimentado pela equipe técnica da FJPO, e os dados são extraídos do formulário de inscrição que os responsáveis das escolas preenchem ao realizarem o agendamento.

Além disso, foi utilizado o Relatório Anual de Atividades da Fundação José Pedro de Oliveira do ano de 2019.

\section{Análise dos dados}

As classes de dados analisados para a realização do perfil de escolas que visitaram a Mata de Santa Genebra no ano de 2019 foram: número de alunos, tipo de instituição sendo municipal, estadual, particular e terceiro setor; ciclos de ensino dividido em infantil, fundamental 1, fundamental 2 e ensino médio, sendo fundamental 1 do $1^{\circ}$ ao $5^{\circ}$ ano e fundamental 2 do $6 \%$ ao 9․ Os dados foram tabulados no Programa Excel e analisados por meio de estatística descritiva.

Com o uso do aplicativo Google Earth Pro mapeou-se os municípios que participaram do Programa Visita Monitorada de Escolas. 


\section{Resultados e Discussão}

De acordo com o Relatório Anual de Atividades da Fundação José Pedro de Oliveira (2019) as atividades do Programa de Uso Público e Educação Ambiental envolveram um público de 14.526 pessoas em 2019. Deste total, 2.510 correspondem a estudantes e professores atendidos pela atividade de Visita Monitorada de Escolas, representando 17,27\% do público total atendido no ano de 2019.

Para o ano de 2019, foram contabilizadas 97 visitas de 50 instituições (Tabela 01). Do total de instituições, 36 eram municipais (72\%), 07 estaduais (14\%), 4 do terceiro setor (8\%) e 3 particulares (6\%).

Em relação aos ciclos de ensino, o Ensino Infantil foi o mais representativo com 57 visitas (58,8\%), seguido do Ensino Fundamental com 21 visitas $(21,6)$ e Ensino Fundamental II com 12 visitas (12,4\%), sendo o menos representativo o Ensino Médio com 7 visitas $(7,2)$ (Tabela 1).

Tabela 1: Dados sistematizados do Programa de Visita Monitorada de Escolas, referente ao ano de 2019.

Table 1: Systematized data from School Visit Program, for the year 2019.

\begin{tabular}{ccllc}
\hline $\begin{array}{c}\text { CLASSE DE } \\
\text { ENSINO }\end{array}$ & $\mathbf{N}^{\mathbf{0}}$ DE ALUNOS & TIPO & CIDADE & $\begin{array}{c}\text { QUANTIDADE } \\
\text { DE VISITAS }\end{array}$ \\
\hline Infantil & 58 & Estadual & Campinas & 3 \\
\hline Infantil & 102 & Municipal & Campinas & 4 \\
\hline Infantil & 17 & Municipal & Campinas & 1 \\
\hline Infantil & 28 & Municipal & Campinas & 2 \\
\hline Infantil & 26 & Municipal & Campinas & 1 \\
\hline Infantil & 49 & Municipal & Campinas & 2 \\
\hline Infantil & 45 & Municipal & Campinas & 1 \\
\hline Infantil & 26 & Municipal & Campinas & 1 \\
\hline Infantil & 31 & Municipal & Campinas & 1 \\
\hline Infantil & 35 & Municipal & Campinas & 1 \\
\hline Infantil & 41 & Municipal & Campinas & 2 \\
\hline Infantil & 23 & Municipal & Campinas & 2 \\
\hline Infantil & 51 & Municipal & Campinas & 2 \\
\hline Infantil & 32 & Municipal & Campinas & 1 \\
\hline Infantil & 98 & Municipal & Campinas & 2 \\
\hline Infantil & 25 & Municipal & Campinas & 1 \\
\hline Infantil & 107 & Municipal & Campinas & 5 \\
\hline Infantil & 15 & Municipal & Campinas & 1 \\
\hline Infantil & 18 & Municipal & Vinhedo & 1 \\
\hline Infantil & 24 & Municipal & Campinas & 1 \\
\hline Infantil & 113 & Municipal & Campinas & 5 \\
\hline Infantil & 17 & Municipal & Campinas & 1 \\
\hline Infantil & 77 & Municipal & Campinas & 3 \\
\hline Infantil & 25 & Campinas & 1 \\
\hline & & & $60 n t i n u a l ~$ & \\
\hline
\end{tabular}

Continua... 


\begin{tabular}{|c|c|c|c|c|}
\hline $\begin{array}{l}\text { CLASSE DE } \\
\text { ENSINO }\end{array}$ & $\mathrm{N}^{\circ}$ DE ALUNOS & TIPO & CIDADE & $\begin{array}{l}\text { QUANTIDADE } \\
\text { DE VISITAS }\end{array}$ \\
\hline Infantil & 12 & Municipal & Campinas & 1 \\
\hline Infantil & 17 & Municipal & Campinas & 1 \\
\hline Ensino médio & 34 & Particular & Campinas & 1 \\
\hline Infantil & 48 & Terceiro Setor & Campinas & 2 \\
\hline $\begin{array}{c}\text { Fundamental } \\
\text { II }\end{array}$ & 40 & Estadual & Campinas & 1 \\
\hline Ensino médio & 87 & Estadual & Campinas & 2 \\
\hline Ensino médio & 38 & Estadual & Hortolândia & 1 \\
\hline $\begin{array}{c}\text { Fundamental } \\
\text { I }\end{array}$ & 47 & Estadual & Campinas & 2 \\
\hline $\begin{array}{c}\text { Fundamental } \\
\text { II }\end{array}$ & 77 & Estadual & Campinas & 2 \\
\hline $\begin{array}{c}\text { Fundamental } \\
\text { II }\end{array}$ & 37 & Estadual & Campinas & 1 \\
\hline $\begin{array}{c}\text { Fundamental } \\
\text { I }\end{array}$ & 54 & Municipal & Campinas & 2 \\
\hline $\begin{array}{c}\text { Fundamental } \\
\text { I }\end{array}$ & 158 & Municipal & Limeira & 4 \\
\hline $\begin{array}{c}\text { Fundamental } \\
\text { I }\end{array}$ & 82 & Municipal & Campinas & 3 \\
\hline $\begin{array}{c}\text { Fundamental } \\
\text { II }\end{array}$ & 156 & Municipal & Campinas & 7 \\
\hline $\begin{array}{c}\text { Fundamental } \\
\text { I }\end{array}$ & 20 & Municipal & Campinas & 1 \\
\hline $\begin{array}{c}\text { Fundamental } \\
\text { I }\end{array}$ & 59 & Municipal & Campinas & 2 \\
\hline $\begin{array}{c}\text { Fundamental } \\
\text { I }\end{array}$ & 93 & Municipal & Campinas & 5 \\
\hline $\begin{array}{c}\text { Fundamental } \\
\text { I }\end{array}$ & 52 & Municipal & Campinas & 2 \\
\hline Infantil & 12 & Municipal & Piracaia & 1 \\
\hline Infantil & 43 & Municipal & Paulínia & 2 \\
\hline Infantil & 85 & Municipal & Paulínia & 3 \\
\hline $\begin{array}{c}\text { Fundamental } \\
\text { II }\end{array}$ & 33 & Particular & Valinhos & 1 \\
\hline Infantil & 9 & Particular & Campinas & 1 \\
\hline Infantil & 24 & Terceiro Setor & Campinas & 1 \\
\hline Ensino médio & 25 & Terceiro Setor & Campinas & 1 \\
\hline \multirow[t]{2}{*}{ Ensino médio } & 85 & Terceiro Setor & Campinas & 2 \\
\hline & 2.510 & & & 97 \\
\hline
\end{tabular}

Fonte: Elaborado pelos autores.

Source: Prepared by the authors.

Das 50 instituições, 43 são oriundas do município de Campinas, representando $86 \%$ das instituições que visitaram a Mata de Santa Genebra em 2019, totalizando 84 visitas (86,59\% das visitas). Outras 7 instituições, são representantes dos municípios de Paulínia (2 instituições), Limeira (1), Valinhos (1), Vinhedo (1), Hortolândia (1) e Piracaia (1), sendo somente a última não pertencendo à Região Metropolitana de Campinas (Figura 2). 
A ARIE Mata de Santa Genebra está localizada no Município de Campinas (BRASIL, 2010), isso pode ter contribuído com o grande número de instituições do município que visitaram a unidade de conservação em 2019.

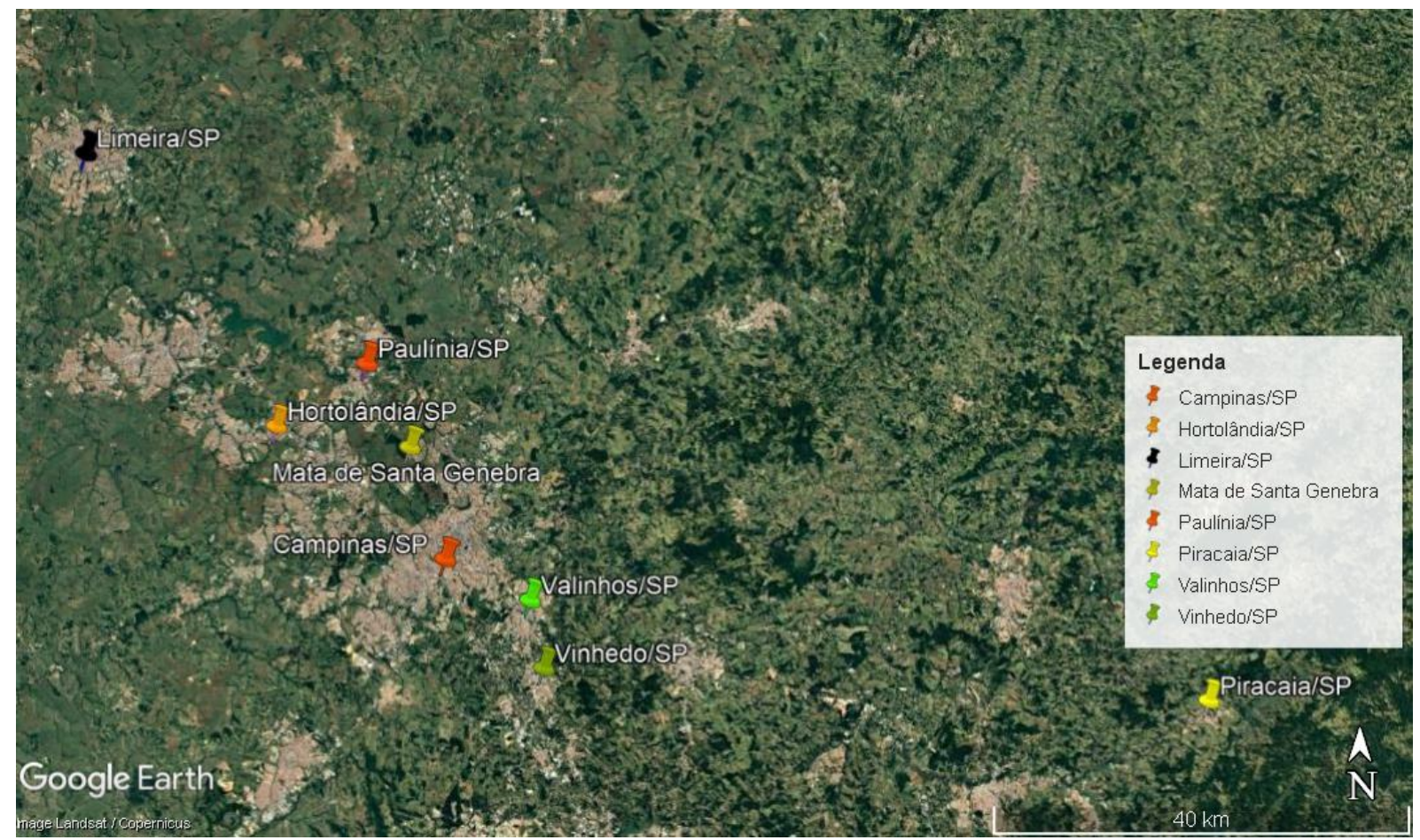

Figura 2: Mapa com os municípios atendidos pelo Programa Visita Monitorada de Escolas no ano de 2019.

Figure 2: Map with the municipalities performed by Visit of Schools Program in 2019.

Fonte: Mapa elaborado pelos autores com Imagem do Google Earth.

Source: Map prepared by the authors with Image from Google Earth.

O município de Campinas possui 321 escolas municipais, 169 estaduais e 246 privadas (ESCOLAS, 2021), totalizando 736 instituições escolares distribuídas entre as seis grandes regiões da cidade. As 43 instituições de Campinas que visitaram a Mata de Santa Genebra em 2019, representaram cerca de 5,84\% das escolas localizadas no município.

Segundo o Plano de Manejo da ARIE Mata de Santa Genebra (BRASIL, 2010), somente dois dias de cada semana são disponibilizados para a realização de visitas de escolas. Os responsáveis pelo agendamento na unidade de conservação, informaram que existe uma grande procura pela atividade e as vagas disponibilizadas esgotam rapidamente, não sendo possível atender todas as instituições. Assim a baixa disponibilidade de dias para a realização de visitas pode ter contribuído para a baixa representatividade de 5,84\% de escolas do município de Campinas que visitaram a ARIE Mata de Santa Genebra em 2019. Apesar disso, as escolas do município correspondem a $86,59 \%$ das visitas realizadas em 2019 , sendo a maioria $(72,10 \%)$ oriunda de escolas municipais (Tabela 2$)$. 
Tabela 2: Tipo de Instituições e quantidade de escolas do município de Campinas que visitaram a Mata de Santa Genebra em 2019.

Table 2: Type of Institutions and amount of Campinas schools who visited the Santa Genebra Forest in 2019.

\begin{tabular}{lccccc}
\hline Setor & Estadual & Municipal & Particular & Terceiro Setor & Total \\
\hline Número de Instituições & 6 & 31 & 2 & 4 & 43 \\
\hline Percentual & $13,95 \%$ & $72,10 \%$ & $4,65 \%$ & $9,30 \%$ & $100,00 \%$ \\
\hline \multicolumn{5}{c}{$\begin{array}{l}\text { Fonte: Elaborado pelos autores. } \\
\text { Source: Prepared by the authors. }\end{array}$} & \\
\end{tabular}

Um fator que pode ter contribuído com a grande representatividade de escolas geridas pelo município de Campinas, é que de acordo com os servidores da Unidade de Conservação a Prefeitura de Campinas disponibiliza ônibus, para que as escolas municipais possam realizar atividades em espaços não formais. Corroborando este dado, o estudo realizado por Oliveira (2014) em duas escolas do município de Peruíbe localizadas nas Unidades de Conservação Estação Ecológica Juréia-Itatins e Zona Tampão do Parque Estadual da Serra do Mar, o acesso e o transporte foram um dos principais problemas apontados por professores para 0 desenvolvimento de atividades ambientais nas unidades de conservação. Este dado foi resultado de um questionário aplicado aos professores (total 24), coordenadores (total 2) e diretores (total 2) (OLIVEIRA, 2014).

A pesquisa realizada por Frizzo (2019) que teve como objetivo identificar estratégias de aproximação entre escolas e unidades de conservação, também apontou a falta de transporte como um fator que prejudica a visita das escolas nas Unidades de Conservação.

A Política Municipal de Educação Ambiental do Município de Campinas (CAMPINAS, 2015) traz como uma de suas diretrizes o fomento e a viabilização de ações socioeducativas nas Unidades de Conservação e em áreas destinadas à conservação ambiental para diferentes públicos, essa política também pode ter contribuído para que a maioria das visitas fossem realizadas por instituições do município de Campinas.

Em relação aos ciclos de ensino, a Educação Infantil foi a mais representativa com 57 visitas, seguida do Ensino Fundamental I com 25 visitas, sendo os menos representativos o Ensino Fundamental II com 8 visitas, e o Ensino Médio com 7 visitas, conforme demonstrado na Figura 3.

O Município de Campinas conta com o Plano Municipal Para a Primeira Infância, que tem o compromisso de pensar e planejar a cidade para as crianças de zero a seis anos de idade para os próximos dez anos (20192029), de modo articulado por diversas esferas do poder público e da sociedade civil (CAMPINAS, 2018). Um dos eixos dispostos no Plano é "A Criança e o Espaço - a cidade e o meio ambiente", que traz como proposta promover e incentivar encontros nos espaços públicos de convivência para exploração do ambiente e desenvolvimento de atividades do brincar, instrumentalizando as famílias para assumirem protagonismo na ocupação e apropriação desses espaços, sendo a Mata de Santa Genebra um espaço para a realização dessas atividades. Essa observação reforça a importância 
das políticas públicas municipais, dada a maior representatividade do ciclo de educação infantil $(58,73 \%)$.

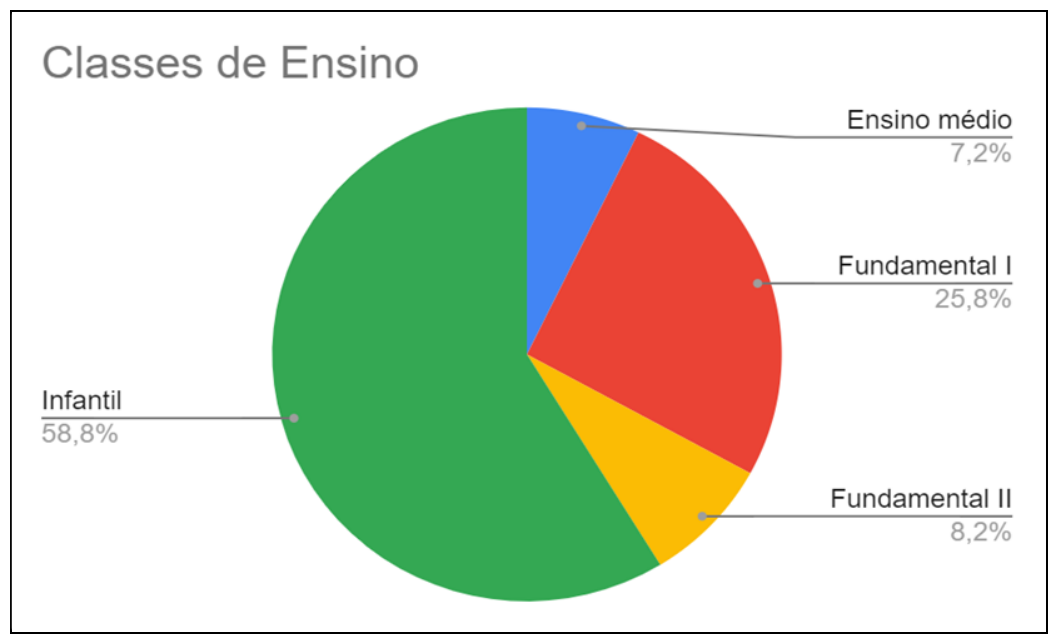

Figura 3: Origem das visitas de acordo com os níveis de ensino.

Figure 3: Origin of visits according to educational levels.

Fonte: Elaborado pelos autores.

Source: Prepared by the authors.

O resultado do mapeamento de distribuição das instituições escolares levantou que todas as regiões do município de Campinas tiveram instituições que visitaram a ARIE Mata de Santa Genebra no ano de 2019 (Figura 4). A maior concentração de escolas é da região sul de Campinas $(27,91 \%)$, seguida da Norte com $25,58 \%$ (Tabela 4). A região do Centro do Município foi a que apresentou o menor número de representantes escolares $(6,98 \%)$.

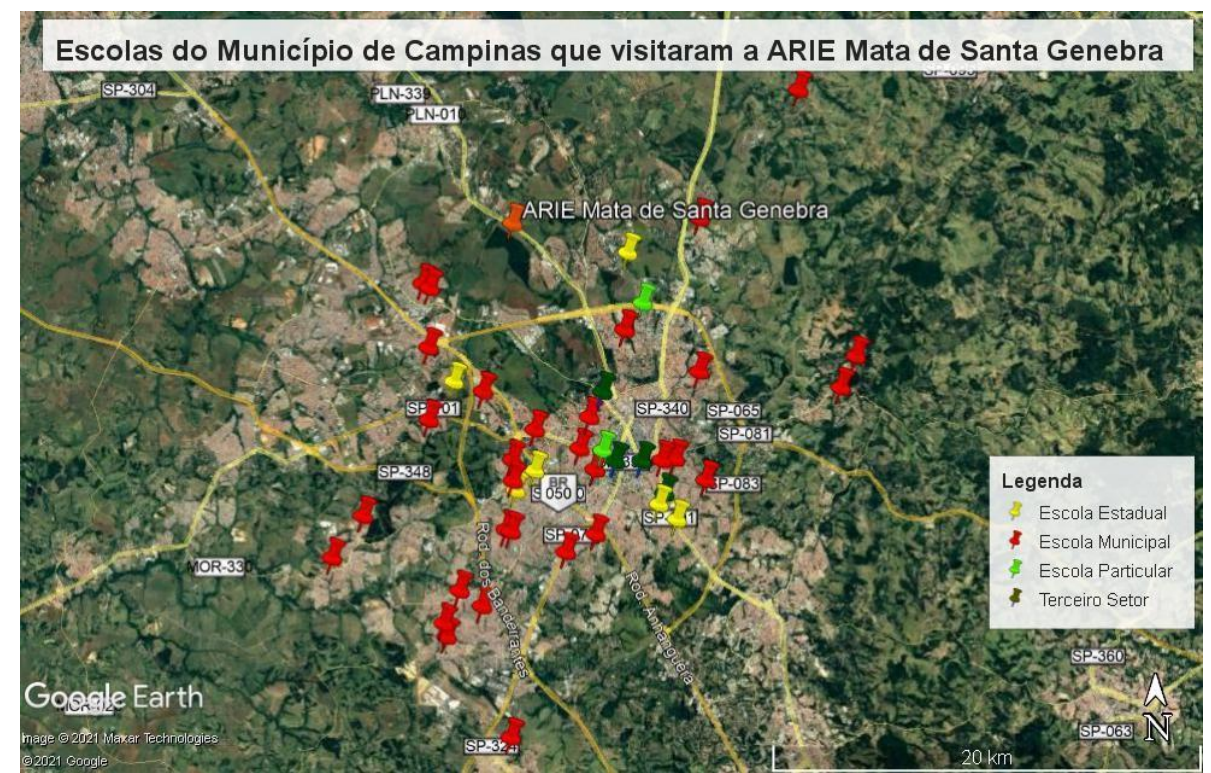

Figura 4: Distribuição das escolas no município de Campinas.

Figure 4: Distribution of schools in the city of Campinas.

Fonte: Mapa elaborado com Imagem do Google Earth.

Source: Map made with Google Earth Image 
Tabela 4: Distribuição das escolas por região no Município de Campinas.

Table 4: Distribution of schools by region in Campinas. Região
№ de instituições
$\%$

\begin{tabular}{lcrr}
\hline Norte & 11 & 25,58 \\
\hline Sul & 12 & 27,91 \\
\hline Leste & 4 & 9,30 \\
\hline Centro & 3 & 6,98 \\
\hline Noroeste & 4 & 9,30 \\
\hline Sudoeste & 9 & 43 & 100,00 \\
\hline & Total & & 43 \\
\hline
\end{tabular}

As principais características da região sul podem ter contribuído com a maior representativa de visitas à ARIE Mata de Santa Genebra. A Macrorregião Sul, está localizada no entorno da área central da cidade, e possui o maior número de habitantes de Campinas, cerca de 260 mil pessoas (CAMPINAS, 2021). Além disso, a região está localizada próximo às principais rodovias e avenidas da Cidade, facilitando o acesso a outras regiões do município.

Já a região norte é a mesma onde está localizada a Mata de Santa Genebra, este fato pode ter contribuído para que a região fosse a segunda com maior representatividade de instituições. Essa região é uma das mais desenvolvidas economicamente de Campinas e onde está instalada umas das maiores e mais conceituadas universidades públicas do país, a Universidade Estadual de Campinas UNICAMP (CAMPINAS, 2021).

Com base na análise dos dados, observa-se como uma fragilidade do Programa de Visita Monitorada de Escolas a baixa participação das instituições estaduais, do terceiro setor e particulares. Além disso, outra fragilidade encontrada foi a baixa participação dos ciclos fundamental I e II, e ensino médio. Assim, é importante o órgão gestor da unidade de conservação criar mecanismos que aproximem as diferentes instituições de ensino com as áreas verdes e fortaleça o sentimento de pertencimento ao meio ambiente.

Segundo Costa e Lopes (2018) a verificação do público e dos atrativos em unidades de conservação devem ser contínuas, a fim de embasar não só o planejamento, mas a atualização constante dos planos de Educação Ambiental de acordo com idade e/ou escolaridade e a finalidade das visitas (COSTA; LOPES, 2018). De acordo com Reigota (2007), existem poucos estudos tratando das relações entre escolas e Unidades de Conservação, reforçando a importância deste trabalho para as ações de Educação Ambiental e uso público para o território sob influência da ARIE Mata de Santa Genebra. 


\section{Considerações Finais}

Com a realização do perfil de escolas, foi possível identificar que a maioria das instituições que visitaram a ARIE Mata de Santa Genebra em 2019 foram municipais. Além disso, o ciclo de educação infantil foi o que mais participou do Programa de Visitas de Escolas.

O Município de Campinas foi o mais representativo em instituições que visitaram a Mata de Santa Genebra em 2019, e isso pode ter ocorrido devido ao incentivo dado pelo município que oferece transporte para as escolas realizarem visitas externas, além dos Planos Municipais de Educação Ambiental e da Primeira Infância do Município de Campinas, que contribuem e incentivam a participação das escolas nos espaços como o da ARIE Mata de Santa Genebra.

Por fim, pode-se concluir que a análise dos dados sistematizados do Programa Visita Monitorada de Escolas constitui uma ferramenta fundamental para levantar fragilidades e potenciais essenciais à gestão de Unidades de Conservação, auxiliando na avaliação das atividades desenvolvidas e na melhoria contínua dos projetos executados.

\section{Referências}

BRASIL. Decreto no 91.885 de 05 de novembro de 1985. Declara como Área de Relevante Interesse Ecológico (ARIE) a Mata de Santa Genebra, no Estado de São Paulo, e dá outras providências. Diário Oficial da União Seção 1 - 06/11/1985, Página 16185. Coleção de Leis do Brasil- 1985, Página 238 Vol. 8 (Publicação Original).

BRASIL. Lei Federal № 9.985, de 18 de julho de 2000. Regulamenta o art. 225, § 10, incisos I, II, III e VII da Constituição Federal, institui o Sistema Nacional de Unidades de Conservação da Natureza e dá outras providências. Disponível em: <http://www.planalto.gov.br/ccivil 03/leis//9985.htm>. Acesso em 13 de novembro de 2020.

BRASIL. Diretrizes para visitação em Unidades de Conservação. Ministério do Meio Ambiente. Secretaria de Biodiversidade e Florestas. Diretoria de Áreas Protegidas. Brasília, 2006.

BRASIL. Ministério do Meio Ambiente. Plano de Manejo ARIE Mata de Santa Genebra. Campinas, 2010. Disponível em <https://www.icmbio.gov.br/ portal/unidadesdeconservacao/biomas-brasileiros/mata-atlantica/unidades-deconservacao-mata-atlantica/2062-arie-mata-de-santa-genebra>. Acesso em 17 de novembro de 2020.

BRASIL. Educação Ambiental em unidades de conservação: Ações voltadas para comunidades escolares no contexto da gestão pública da biodiversidade. Instituto Chico Mendes de Conservação da Biodiversidade ICMBIO, Brasília, 2016. Disponível em: <https://www.icmbio.gov.br/ portal/images/stories/comunicacao/publicacoes/publicacoesdiversas/DCOM I CMBio educacao ambiental em unidades de conservacao.pdf>. Acesso em: 14 novembro de 2020.

BRASIL, Política Nacional de Educação Ambiental - Lei no 9.795, de 27 de abril de 1999. Disponível em: <http://www.planalto.gov.br/ccivil 03/leis/l9795.htm>. Acesso em 24 de janeiro de 2021. 
CAMPINAS. PMC-SMVMADS. Política Municipal de Educação Ambiental no Município de Campinas. Lei no 14.961 de 06 de janeiro de 2015.

CAMPINAS. PMC-SMVMADS. Plano Municipal de Educação Ambiental, 2016. Disponível em <http://www.campinas.sp.gov.br/arquivos/meioambiente/pmea-volume-ii.pdf>. Acesso em 12 de novembro de 2020.

CAMPINAS. PMC-SE. Plano Municipal Para a Primeira Infância. 2018.

CAMPINAS. PMC-SSP, Conheça a sua região. Disponível em: $<$ http://www.campinas.sp.gov.br/governo/servicos-publicos/regioes/>. Acesso em: 12 de janeiro de 2021.

CNUC - Cadastro Nacional de Unidades de Conservação. Disponível em: $<$ https://antigo.mma.gov.br/areas-protegidas/cadastro-nacional-de-ucs.html>.

Acesso em 05 de dezembro de 2020.

CORNELL, J. Vivências com a natureza. São Paulo, Aquariana, 2005.

COSTA, J. M.; LOPES, A. F. Uma Análise sobre o potencial de visitação e atividades educativas na Área de Proteção Ambiental do Engenho Pequeno, São Gonçalo, RJ. Diversidade e Gestão 2(2): 198-218. 2018 Volume Especial: Conservação in situ e ex situ da Biodiversidade Brasileira eISSN: 2527-0044 <https://itr.ufrri.br/diversidadeegestao/wpcontent/uploads/2019/02/Alexandre-Lopes.pdf>.

ESCOLAS. Número de escolas no município de Campinas. $<$ http://www.escolas.inf.br/sp/campinas $>$. Acesso em 15/01/2021

FUNDAÇÃO JOSÉ PEDRO DE OLIVEIRA. Relatório Anual de Atividade, 2019.

FUndAÇÃO JOSÉ PEDRO DE OLIVEIRA. Plano Político Pedagógico Centro de Educação Ambiental ARIE Mata de Santa Genebra.. CampinasSP, 2018.

HINTZE, H. Ecoturismo na cultura de consumo: possibilidade de Educação Ambiental ou espetáculo? Jundiaí: Paco Editora, 2013.

KRIPPENDORF, J. Sociologia do turismo: para uma nova compreensão do lazer e das viagens. 3 ed. São Paulo: Aleph, 2003. 184 p.

LEITÃO FILHO, H. F.; MORELLATO, P. C. Floresta tropical urbana: reserva de Santa Genebra. Campinas: Editora da Unicamp, 1995. 136p.

MEDEIROS, R. Evolução das tipologias e categorias de áreas protegidas no Brasil. Ambiente \& Sociedade, Campinas, v.9, n.001, p.41-64, 2006.

NEIMAN, Z. A Educação Ambiental através do contato dirigido com a natureza. 2007. 234 f. Tese (Doutorado em Psicologia) - Universidade de São Paulo, 2007.

NIEFER, I. A. Análise do perfil dos visitantes das Ilhas do Superagüi e do Mel: marketing como instrumento para um turismo sustentável. $237 \mathrm{f}$. Tese (Doutorado em Ciências Florestais) - Setor de Ciências Agrárias, Universidade Federal do Paraná, Curitiba, 2002.

OLIVEIRA, C. N., A Educação Ambiental e o ensino de geociências em unidades de conservação: O papel interlocutor da escola no município de Peruíbe (SP). Tese apresentada ao Instituto de Geociências da Unicamp para obtenção do título de Doutor em Ciências. Campinas-SP, 2014. 
PALMIERI, M.L.; MASSABNI, V.G. Visitas escolares em áreas protegidas do Estado de SP. Rev. Inst. Flor. v. 32 n. 1 p. 17-28 jun. 2020

PIRES, P.S. Dimensões do Ecoturismo. São Paulo: SENAC, 2002. 269 p.

REIGOTA, M. O estado da arte da pesquisa em Educação Ambiental no Brasil. Pesquisa Educação Ambiental. 2007, vol.2, n.1, pp. 33-66.

RUSCHMANN, D. Van de M. Turismo no Brasil: análise e tendências. Barueri, SP: Manole, 2002. 165 p.

SAVI, M. Manejo de visitantes para implementação de Parques - estudo de caso Parque Estadual Marumbi. Anais do Congresso Brasileiro de Unidades de Conservação, v. 2, p. 391-403. Curitiba. Universidade Livre do Meio Ambiente: Rede Nacional Pró-Unidades de Conservação, Curitiba-PR, 1997.

SILVA, R. L. C; COUTINHO, S. F.S. Unidades de conservação como ferramenta de estudo das questões ambientais nas aulas de geografia. Anais do IV Congresso Nacional de Educação, 2017.

VASCONCELLOS, J. M. de O. Educação e Interpretação Ambiental em Unidades de Conservação. Cadernos de Conservação, ano 3, n 4. Curitiba: O Boticário. 2006. 86p.

Sabrina Kelly Batista Martins: Universidade Federal de São Carlos,

Sorocaba, SP, Brasil.

E-mail: sabrinakelbm@gmail.com

Link para o currículum Lattes: http://lattes.cnpq.br/3312168249417164

Ismail Barra Nova de Melo: Universidade Federal de São Carlos, Sorocaba, SP, Brasil.

E-mail: ismail@ufscar.br

Link para o currículum Lattes http://lattes.cnpq.br/3576937472687059

Rita de Cássia Lana: Universidade Federal de São Carlos, Sorocaba, SP, Brasil.

E-mail: lanarc@ufscar.br

Link para o currículum Lattes http://lattes.cnpq.br/1816504631940006

Silvio César Moral Marques: Universidade Federal de São Carlos, Sorocaba, SP, Brasil.

E-mail: silviocmm@ufscar.br

Link para o currículum Lattes http://lattes.cnpq.br/6047434055828372 